\title{
Interleukin 15 and Eotaxin correlate with the outcome of breast cancer patients vice versa independent of CTC status
}

\author{
Theresa Vilsmaier ${ }^{1} \cdot$ Helene Hildegard Heidegger $^{1}$. Lennard Schröder ${ }^{1}$. Elisabeth Trapp ${ }^{2}$ • Alaleh Zati zehni ${ }^{1}$. \\ Brigitte Rack $^{3}$. Wolfgang Janni ${ }^{3}$. Sven Mahner ${ }^{1} \cdot$ Tobias Weissenbacher $^{4} \cdot$ Udo Jeschke $^{1}$ (1) Jan-Niclas Mumm ${ }^{5}$. \\ SUCCESS Study Group
}

Received: 9 May 2020 / Accepted: 5 September 2020 / Published online: 14 September 2020

(c) The Author(s) 2020

\begin{abstract}
Background Circulating tumor cells (CTC) in the peripheral blood in women with breast cancer has been found to be an indicator of prognosis before the start of systemic treatment. The aim of this study is the assessment of specific cytokine profiles as markers for CTC involvement that could act as independent prognostic markers in terms of survival outcome for breast cancer patients.

Methods Patients selected for this study were defined as women with breast cancer of the SUCCESS study. A total of 200 patients' sera were included in this study, 100 patients being positive for circulating tumor cells (CTC) and 100 patients being CTC negative. The matching criteria were histo-pathological grading, lymph node metastasis, hormone receptor status, TNM classification, and patient survival. Commercial ELISA with a multi cytokine/chemokine array was used to screen the sera for Interleukin 15 (IL-15) and eotaxin.

Results Statistically significant concentrations were exposed for IL-15 levels regardless of the CTC-Status, lymph node involvement, or hormone receptor status. Significantly enhanced serum IL-15 concentrations were observed in those patients with worse overall survival (OS) and disease-free survival (DFS). Elevated serum concentrations of IL-15 significantly correlate with patients diagnosed with Grade 3 tumor and worse OS. In contrast, patients with a Grade 3 tumor with a favourable OS and DFS demonstrated significantly decreased IL-15 values. The CTC negative patient subgroup with a favourable OS and DFS, showed statistically significant elevated eotaxin values.

Conclusion These findings suggest a potential functional interaction of increased IL-15 concentrations in the peripheral blood of patients with a worse OS and DFS, regardless of prognostic factors at primary diagnosis. The increased levels of the chemokine eotaxin in CTC negative patients and a favourable OS and DFS, on the other hand, suggest that the overexpression inhibits CTCs entering the peripheral blood, thus emphasizing a significant inhibition of circulation specific metastasis. To sum up, IL-15 could be used as an independent prognostic marker in terms of survival outcome for breast cancer patients and used as an early indicator to highlight high-risk patients and consequently the adjustment of cancer therapy strategies.
\end{abstract}

Keywords SUCCESS study $\cdot$ Breast cancer $\cdot$ Circulating tumor cells $\cdot$ Interleukin $15 \cdot$ Eotaxin

\section{Abbreviations}

CTC Circulating tumor cells

ELISA Enzyme-linked immunosorbent assay

TH1 Thelper 1
TH2 Thelper 2

Treg Regulatory T cells

IL-15 Interleukin 15

DFS Disease-free survival
Udo Jeschke

udo.jeschke@med.uni-muenchen.de

1 Department of Gynecology and Obstetrics, Ludwig Maximilian University, Maistraße 11, 80337 Munich, Germany

2 Department of Gynecology and Obstetrics, University Hospital Graz, Auenbruggerplatz 14/1, 8036 Graz, Austria
3 Department of Gynecology and Obstetrics, University Hospital Ulm, Prittwitzerstr. 43, 89075 Ulm, Germany

4 Department of Gynecology, Waldstraße 7, 82166 Gräfelfing, Germany

5 Department of Urology, Ludwig Maximilian University, Marchioninistraße 15, 81377 Munich, Germany 
OS Overall survival

AUC Area under the curve

FEC Fluorouracil-epirubicin-cyclo-phosphamide

NK Natural killer

DC Dendritic cells

HER2 Human epidermal growth factor receptor 2

\section{Introduction}

Breast cancer is the most common malignant tumor in women; yet invasive breast cancer is still considered one of the greatest challenges for experts to control and thereby improve the survival of patients [1]. The options for treatment of breast cancer comprise targeted therapies, chemotherapy, surgery, radiotherapy, aromatase inhibitors, and hormone-receptor modulators [2-4]. Even though the options have advanced extremely over the past years, the consistently high mortality rate, due to tumor metastasis to the lymph node and vital organs, remains [5]. Its mortality is mostly due to distant metastatic growth $[5,6]$.

The expression 'liquid biopsy' describes the observation and evaluation of treatment effectiveness in patients with breast cancer and refers to molecular analysis of the tumor's genetic structures based on circulating genetic material in the peripheral blood derived from circulating tumor cells (CTCs) [7, 8]. The technology for detecting CTCs has progressed from simple cell counting into advanced molecular subtyping [9], and as a minimally invasive method it could be of tremendous importance in the future for early cancer identification and disease monitoring. The correlation between poor prognosis and the detection of CTCs before the start of systemic treatment has been described previously [10]. CTCs in the peripheral blood have been determined to be a prognostic marker for reduced disease-free survival (DFS), distant DFS and overall survival (OS) before the start of systemic treatment in both metastatic and non-metastatic breast cancer [10-14]. As CTCs are believed to originate from the primary tumor and to acquire genetic heterogeneity during evolution, CTC values also provide complementary information concerning the treatment response [14]. The SUCCESS study was one of the first trials to determine the prognostic association of CTCs with poorer survival in early breast cancer, before the start of systemic adjuvant treatment, and after adjuvant chemotherapy, in a large patient collective [15].

In order to understand the cause for CTC involvement, maturity, and outcomes, cytokine measurements in cancer therapy have become increasingly crucial [16]. As the involvement of the lymphatic system is known to play a key role in the progression of breast cancer [17], the aim of this study was the evaluation of Interleukin 15 (IL-15) and eotaxin as markers for CTC involvement in patients with the primary diagnosis of breast cancer. Cytokines and chemokines, through their tumor-promoting or tumorsuppressive properties, leading to the expression of either pro-inflammatory or anti-inflammatory cytokines [18], are able to trigger cancer progression and are presumed to be an important prognostic factor in the presence of breast cancer tumors [19]. Helper T-lymphocyte maturation depends on the arrangement of cytokines and results in the stimulation or suppression of critical cell derivation $[20,21]$. One such pro-inflammatory cytokine is IL- 15 . IL-15 has early been identified as a $14-18 \mathrm{kDa}$ protein [22]. The IL-15 structure produced in humans is described as a four $\alpha$-helical bundle cytokine, positioned on chromosome $4 \mathrm{q} 31$ [22]. IL-15 was found to practice its biological effects, exploiting two separate signalling pathways. One of these paths encloses the conventional binding and signalling through the IL-15 receptor $\alpha$ (IL-15R $\alpha$ ), $\beta$ and $\gamma$ chains $[22,23]$. This pathway is of interest as it has been described to result in the up-regulation of natural killer cells and T-cell activity in the human immune system [23-25]. The studies concerning IL-15 so far have already focused on its role concerning tumor genesis and its effect on proliferation, invasion, and metastasis production. IL-15 has predominantly been investigated in haematological malignancies [26-28] and is associated with a range of inflammatory disorders [25, 29]. The expression of IL-15 has been described as a protective factor in tumor genesis and against tumor progression in certain publications [30, 31], but in advanced solid cancers IL-15 expression acts contrarily thus contributing to disease progression [32-35]. Recently, studies demonstrated that IL-15 detected in sera of patients could provide neoplastic cells with a selective growth advantage in inducting and promoting certain types of malignancies $[28,36]$. In regards to haematological malignancies, Cario et al. implied that IL-15 may increase cellular proliferation and is associated with poor prognosis in regards to relapse-free survival [37]. In a similar study by Chow et al., the serum levels of IL-15 were increased significantly in cancer patients compared to healthy individuals [38]. Eotaxin on the other hand is known to selectively recruit eosinophils, enhancing anti-tumor effects $[39,40]$.

The inconsistency of increased IL- 15 levels acting both as a positive or negative marker in regard to tumor progression and survival outcome, could be explained by the role of dendritic cells (DCs) and their effect on the Immune system. DCs are known to be one of the most potent types of antigen-presenting cells in the human body and are involved in the regulation of both distinctive and adaptive immune responses [41]. DCs could therefore be of major importance concerning the effectiveness of IL-15 and its influence on survival outcome, and should be considered for future studies. 
As no specific characteristics were described so far in relation to breast cancer, our goal was to examine the value of IL-15 in the T-lymphocyte immune response and the chemokine eotaxin, to reveal differences in the presence or absence in patients with breast cancer of the SUCCESS study; examining this with respect to CTC involvement, histopathological grading, lymph node status, hormone receptor type, OS, and DFS.

Detection of certain cytokine profiles and evaluation of their features can contribute to our better understanding of the disease, customized treatment options, and improved therapy observation. The tumor cell features in relation to cytokine profiles, their effect on the autoimmune response and changes in the microenvironment at the homing site, are of major importance for the future and therefore could be of use in generating new therapies.

\section{Materials and methods}

\section{SUCCESS study design}

SUCCESS was a prospective, randomized adjuvant study comparing three cycles of fluorouracil-epirubicincyclo-phosphamide (FEC; 500/100/500 mg/ $\mathrm{m}^{2}$ ) followed by 3 cycles of docetaxel $\left(100 \mathrm{mg} / \mathrm{m}^{2}\right)$ every 3 weeks vs. three cycles of FEC followed by 3 cycles of gemcitabine $\left(1000 \mathrm{mg} / \mathrm{m}^{2} \mathrm{~d} 1,8\right)$-docetaxel $\left(75 \mathrm{mg} / \mathrm{m}^{2}\right)$ every 3 weeks. After the completion of chemotherapy, the patients were randomized a second time to receive either 2 or 5 years of zoledronate. Hormone receptor-positive women, moreover, received applicable endocrine treatment.

The translational research questions related to CTC analysis, the blood sampling time points, and the methodology, were accordingly designed, and the prognostic value of the CTCs was described as a scientific objective of the study protocol. Eligible patients were defined as women with breast cancer (Lymph node positive subgroup and Lymph node negative subgroup with high risk traits including grade 3 tumor, hormone receptor negative, age under $35, \geq \mathrm{pT} 2$ ) who agreed to participate in the SUCCESS study (www. success-studie.de). The study was permitted by 37 German ethical boards (lead ethical board: LMU, Munich) and conducted in agreement with the Declaration of Helsinki.

\section{Blood sample collection for CTC enumeration}

Blood samples for CTC enumeration were collected after study inclusion from 2090 consecutive patients after complete resection of the primary tumor and before adjuvant chemotherapy and after written informed consent was acquired. Sixty-four patients were excluded because of test failure or a time intermission of more than $96 \mathrm{~h}$ between the blood collection and sample preparation. A follow-up evaluation after chemotherapy and before the beginning of endocrine or bisphosphonate treatment was available for a subgroup of 1492 patients (see homepage: https://www. success-studie.de).

The method was conducted as described by the SUCCESS Study group [15]. CTCs were investigated using the CellSearch System (Veridex, Jansen Diagnostics, NJ, USA). Peripheral blood was drawn into three CellSave tubes $(30 \mathrm{ml})$, sent at room temperature to the central laboratory at the University of Munich, and examined within $96 \mathrm{~h}$ of collection.

The patient samples were then centrifuged for $10 \mathrm{~min}$ at $800 \times g$. The plasma was removed, and a dilution buffer was supplemented. This combination was overlaid on $6 \mathrm{ml}$ of Histopaque (Sigma, Steinheim, Germany) and centrifuged for $10 \mathrm{~min}$ at $400 \times \mathrm{g}$. Subsequently, $7.5 \mathrm{ml}$ of this sample enclosing the buffy coat were treated on the CellTracks AutoPrep system using the CellSearch Epithelial Cell Kit (Veridex). After immuno-magnetic enrichment with an antibody to Epithelial cell adhesion molecule (EpCAM), the cells were marked with fluorescent anti-cytokeratin (CK8,18,19-phycoerythrin) and anti-CD45 (CD45-allophycocyan) antibodies, and 4,6-diamidino-2-phenyl-indoledihydrochloride was used to identify the intact cells.

\section{Detection of CTCs}

The identification and enumeration of CTCs were achieved using the CellTracks Analyzer II. CTCs were stated as nucleated cells lacking CD45 and expressing cytokeratin. All positive samples were assessed by two independent investigators. Samples with at least one CTC per $30 \mathrm{ml}$ of blood were regarded as CTC-positive.

The blood of 84 persons with no clinical evidence of malignant disease was processed blind and used as a negative control. Four of these negative controls (4.9\%) contained cells that fit the definition of epithelial cells and which could be interpreted as CTCs (one control had one, two controls had two, and one control had three epithelial cells).

\section{Patients included}

In this study 200 patients of the SUCCESS study were included and assigned into two groups: 100 Patients were CTC-positive (Group 1) and the other 100 patients were CTC-negative (Group 2). These two groups were framed and investigated accordingly. Patients from, respectively, groups were matched into pairs of two according to histo-pathological grading, lymph node involvement, hormone receptor type, and TNM classification. Furthermore, patients were matched according to OS (survived patients vs. deceased patients) at the end of the follow-up period. Out of 200 
patient samples that were investigated, 160 patients were still alive at last observation at end of therapy and 40 patients had died during therapy. The groups investigated included 98 patients with tumor graded G2 and 102 patients graded G3. Matching criteria of the patient collective did not allow participants with G1 tumors (see Table 1). Tumor stage of the anamnestic diagnosis was classified according to the TNM-classification, which was conducted according to the WHO System [42]. The matching of patients was performed according to the criteria at the time of primary diagnosis. The histo-pathological grading was classified according to the Bloom and Richardson system classification [43].

\section{Follow-up and patient evaluation}

The median follow-up was 65 months (range 1-96 months). All time-to-event intervals were measured from time of the primary diagnosis to the date of the event or the date of the last adequate follow-up in case no event was reported. Patient outcomes were examined in terms of both DFS and OS. The patients were monitored at the study sites at 3 -month intervals for the first 3 years, followed by every 6 months thereafter. The follow-up involved clinical examination and symptom-driven analyses, if necessary, at each visit, and mammography every 6 months. The collected data were acquired from the electronic case record forms of the SUCCESS study [15].

\section{Cytokine determination}

For the measurement of cytokines, a commercial enzymelinked immunosorbent assay (ELISA) was used to screen the blood serum samples for IL-15 and eotaxin. The ELISA was preformed with recently developed multi cytokine/ chemokine arrays acquired by Meso Scale Discovery ${ }^{\circledR}$ (Rockville, MD, USA). We used anti-species MULTIARRAY 96-well plates for the development of a sandwich immunoassay. Each assay in the panel was verified individually for the Specificity by running single calibrators with single detection antibodies. Non-specific binding levels were less than $0.5 \%$ for all assays. The 10 spot MULTI-SPOT plates were pre-coated with capture antibodies on independent and well defined spots that allowed us to immobilize a primary capture antibody against our protein of interestspecific for one of each vascular marker. Standards and samples were added to the appropriate wells. A standard curve was furthermore run with each assay. We firstly added the blood serum, calibrator and control. Subsequently we incubated at room temperature with shaking for $2 \mathrm{~h}$. After eliminating excess samples from the well with wash buffer, we added the detection (anti-target) antibody conjugated with electrochemiluminescent labels over the course of two incubation periods. During the incubation period, where time
Table 1 Patient and tumor characteristics

\begin{tabular}{|c|c|c|}
\hline Characteristics & $\begin{array}{l}\text { Alive patients } \\
\text { after follow-up } \\
\text { No. }(\%)\end{array}$ & $\begin{array}{l}\text { Deceased } \\
\text { patients after } \\
\text { follow-up } \\
\text { No. }(\%)\end{array}$ \\
\hline No. of patients & 160 & 40 \\
\hline Age in years $($ mean $\pm S D)$ & $54.2 \pm 9.6$ & $53.3 \pm 10.1$ \\
\hline \multicolumn{3}{|l|}{ CTC status } \\
\hline CTC negative $(\mathrm{CTC}=0 \#)$ & $80(50)$ & $20(50)$ \\
\hline CTC positive $(\mathrm{CTC} \geq 1 \#)$ & $80(50)$ & $20(50)$ \\
\hline \multicolumn{3}{|l|}{ Tumour size } \\
\hline pT1a-c & 78 (48.7) & $10(25.0)$ \\
\hline pT2-4 & $82(51.3)$ & $30(75.0)$ \\
\hline \multicolumn{3}{|l|}{ Lymph node status } \\
\hline pN0 (node negative) & $54(33.8)$ & $8(20.0)$ \\
\hline pN1 (1-3 axillary) & $82(51.2)$ & $12(30.0)$ \\
\hline pN2 (4-9 axillary) & $22(13.7)$ & $16(40.0)$ \\
\hline pN3 ( $\geq 10$ axillary) & $2(1.3)$ & $4(10.0)$ \\
\hline \multicolumn{3}{|l|}{ Grading } \\
\hline $\mathrm{G} 2$ & $88(55.0)$ & $10(25.0)$ \\
\hline G3 & $72(45.0)$ & $30(75.0)$ \\
\hline \multicolumn{3}{|l|}{ Hormone receptor status } \\
\hline Negative & $44(27.5)$ & $10(25.0)$ \\
\hline Positive & $116(72.5)$ & $30(75.0)$ \\
\hline \multicolumn{3}{|l|}{ Her2-neu status } \\
\hline Negative & $28(17.5)$ & $30(75.0)$ \\
\hline Positive & $132(82.5)$ & $10(25.0)$ \\
\hline \multicolumn{3}{|l|}{ Menopausal status } \\
\hline Premenopausal & $69(43.1)$ & $14(35.0)$ \\
\hline Postmenopausal & $91(56.9)$ & $26(65.0)$ \\
\hline \multicolumn{3}{|l|}{ Primary operation } \\
\hline Breast conserving & $113(70.6)$ & $29(72.5)$ \\
\hline Mastectomy & $47(29.4)$ & $11(27.5)$ \\
\hline \multicolumn{3}{|l|}{ Systematic therapy } \\
\hline Chemotherapy-FEC-D & $76(47.5)$ & $21(52.5)$ \\
\hline Chemotherapy-FEC-DG & $84(52.5)$ & $19(47.5)$ \\
\hline
\end{tabular}

${ }^{\circ}$ Median follow-up was 65 months (range 1-96 months)

*CTC circulating tumour cell, FEC-D fluorouracil-epirubicin-cyclophosphamide $\left(500 / 100 / 500 \mathrm{mg} / \mathrm{m}^{2}\right.$, FEC) followed by doxetacel $\left(100 \mathrm{mg} / \mathrm{mg}^{2}\right), F E C-D G$ fluorouracil-epirubicin-cyclophosphamide $\left(500 / 100 / 500 \mathrm{mg} / \mathrm{m}^{2}\right.$, FEC) followed by gemcitabine $\left(1.000 \mathrm{mg} / \mathrm{m}^{2}\right.$ d1,8)-doxetaxel $\left(75 \mathrm{mg} / \mathrm{m}^{2}\right)$

\#Per $30 \mathrm{ml}$ of blood

slots differed in each test, the target present in the sample bound to the capture antibody, which was immobilized on the working electrode surface by the anti-species antibody. Recruitment of the labelled detection antibody by the bound target completed the sandwich. After a second shaking incubation period (time differed for each test) a wash buffer was used to eliminate all the unbound enzymes, and a MSD Read Buffer was added to produce the suitable chemical 
environment for electrochemiluminescence. We then loaded the plate into an MSD instrument (MESO QuickPlex SQ 120) for examination where voltage applied to the plate electrodes caused the captured labels to emit light. The intensity of the emitted light presented a quantitative measure for the amount of protein of interest present in the sample [44, 45] (see homepage: www.mesoscale.com).

\section{Statistical analysis}

Statistical analysis was accomplished using SPSS 24.0 (IBM Corp., Armonk, NY, USA). The outcomes collected were recorded and inserted into the SPSS database in the implied manner. We evaluated the relationship between IL-15 and eotaxin and each matching criterion (CTC-positive vs. CTCnegative; OS -survival vs. death; grade 2 vs. grade 3 ; lymph node involvement vs. no lymph node involvement; triplepositive- vs. triple-negative breast cancer; progesterone receptor-positive vs. progesterone receptor-negative; oestrogen receptor-positive vs. oestrogen receptor-negative; HER2/ neu receptor-positive vs. HER2/neu receptor-negative) using the non-parametric Spearman correlation coefficient. Each parameter to be considered was required to have a $p$-value of less than 0.05. Statistically significant results for the Spearman correlation coefficient were then assessed with the non-parametric Mann-Whitney U rank-sum test. Moreover, variables were examined by the use of box-plot analysis. All statistical tests were considered significant at $p<0.05$.

\section{Results}

\section{CTC-positive vs. CTC negative patients}

In the overall patient collective, statistically significant differences were shown for IL-15 values in regard to the CTCstatus. Amongst the CTC-negative group, those patients who died during the follow-up period expressed significantly higher levels of IL-15 compared to those patients being CTC-negative who were living at follow-up. This cohort expressed low levels of IL-15. The Spearman correlation coefficient assessed the p-value of 0.008 which was moreover supported by the Mann-Whitney- $U$-Test $p=0.008$. ROC analysis implemented an AUC value of 0.688 (see Fig. 1a).

Furthermore, analysis amongst the CTC-positive collective showed that patients who died during the followup period, displayed significantly higher levels of IL-15 in comparison to CTC-positive patients who were living at follow-up; revealing expressively low levels of IL-15. The Spearman correlation coefficient evaluated the $p$-value at 0.001 which was reinforced by the Mann-Whitney- $U$-Test $p=0.001$. ROC analysis was executed, revealing an AUC value of 0.729 (see Fig. 1b).

\section{Lymph node involvement}

The patient collective with lymph node metastasis indicated statistically significant differences in regard to the patient survival outcome in correlation to IL-15 levels. Box-plot analysis showed that patients with lymph node metastasis who died during the follow-up period demonstrated considerably increased IL-15 values in contrast to the notable low IL-15 levels in patients with lymph node metastasis who were living at follow-up. The spearman correlation coefficient calculated the $p$-value at 0.001 which was furthermore confirmed by the Mann-Whitney- $U$-Test $p=0.001$. ROC analysis assessed the AUC value at 0.697 (see Fig. 2a).

Moreover, a statistically significant correlation was also proven for the collective with no lymph node metastasis in association to the IL-15 levels and patient survival. The box plot analysis revealed that the collective of patients with no lymph node involvement (N0) who nonetheless died in the follow-up period, demonstrated significantly higher levels of IL-15 values in distinction to the notable low IL-15 levels in patients who remained alive. The Spearman correlation coefficient evaluated the $p$-value at 0.013 which was furthermore supported by the Mann-Whitney $U$ Test $p=0.014$. ROC analysis was executed, revealing an AUC value at 0.755 (see Fig. 2b).

\section{Hormone receptor status}

In the total patient collective, statistically significant differences were shown for IL-15 values regarding the hormone receptor status. Patients with a triple-negative breast cancer (TNBC; progesterone receptor negative, oestrogen receptor negative, HER-2-neu receptor negative) who died during the follow-up period, expressed drastically higher levels of IL-15 as opposed to decreased IL-15 levels in patients who remained alive and showed a positive OS and DFS. The Spearman correlation coefficient assessed the $p$-value at 0.011 , supported by the Mann-Whitney $U$ Test $p=0.010$. ROC analysis was executed, revealing an AUC value of 0.779 (see Fig. 3a).

Finally, patients with triple-positive breast cancer who died while showing poor OS and DFS also displayed significantly higher levels of IL-15, in contrast to those patients who remained alive with a triple-positive breast cancer. The latter showing significantly low IL-15 levels. The Spearman correlation coefficient disclosed a $p$-value of 0.002 . Mann-Whitney- $U$-Test calculated $p=0.003$. ROC analysis gave an AUC value of 0.681 (see Fig. 3b).

\section{Grading}

The data collected implies statistically significant differences concerning IL-15 levels in patients with a Grade 3 


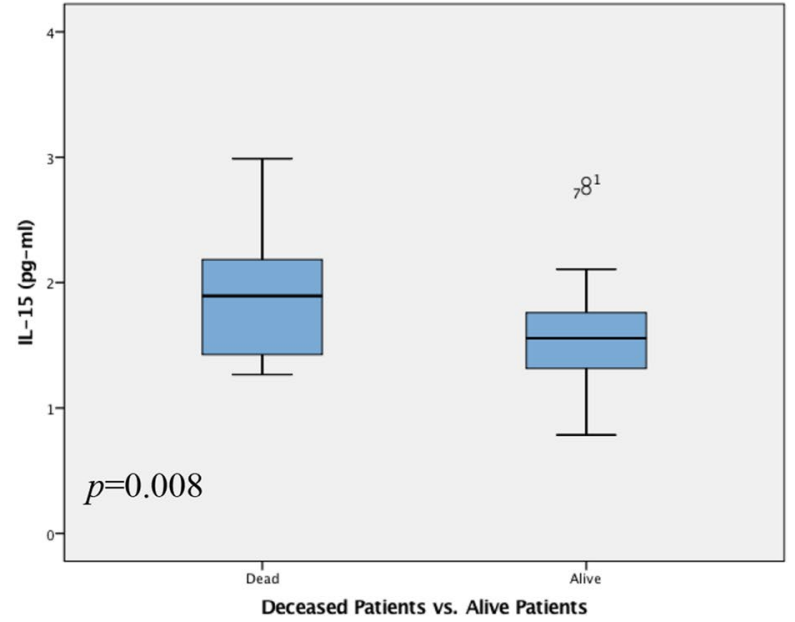

(a)

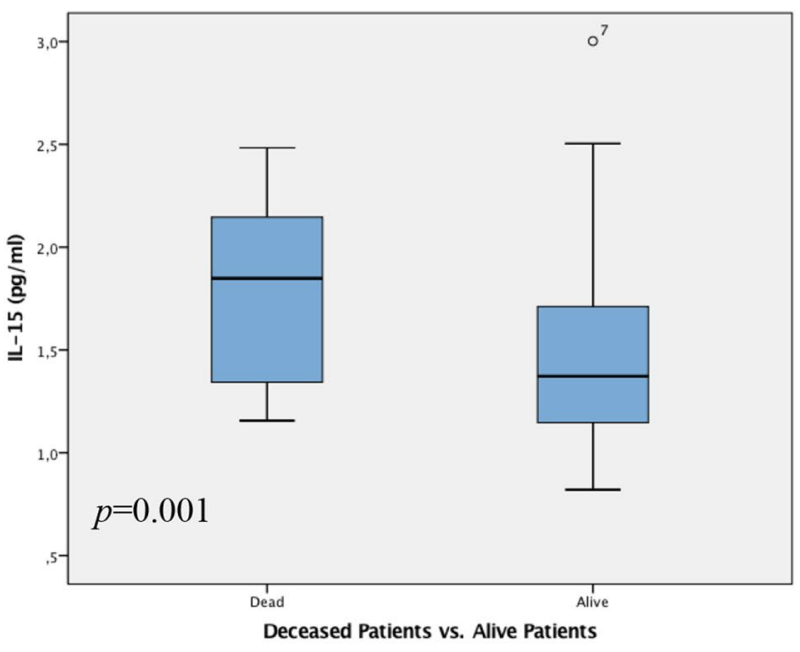

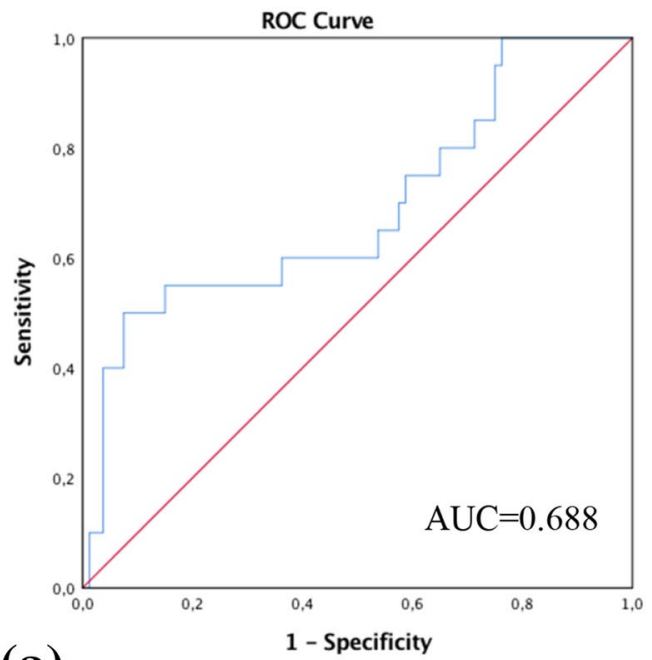

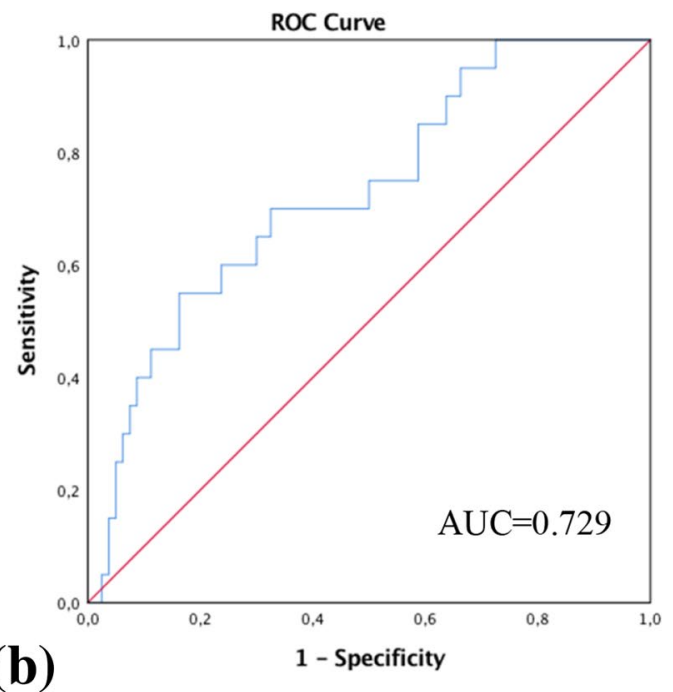

Fig. 1 a Box plot analysis of Interleukin 15 expression (IL-15) in the sera of patients with CTC-negative breast cancer. IL-15 release was significantly higher in patients who died compared to patients who were living at follow-up $(p=0.008)$. Receiver operator curve analysis of sensitivity versus specificity gave an area under the curve (AUC) of 0.688 (a). b Box plot analysis of IL-15 expression and patients with CTC-positive disease. IL-15 release was expressively higher in the patient collective who died in the follow-up period compared to the living patient group ( $p=0.001$ ). Receiver operator curve analysis of sensitivity versus specificity gave an AUC of 0.729 . The range amongst the 25th and 75th percentiles is demonstrated by boxes with a horizontal line at the median. The bars display the 5th and 95th percentiles. Circles specify values more than 1.5 box lengths. Asterisks specify values (marked with a number) more than 3.0 box lengths from the 75 th percentile tumor (G3) in respect to OS and DFS. Patients with a G3 tumor, who died in the follow-up period, showed considerably increased IL-15 values, in contrast to the significantly decreased IL-15 levels in patients with G3 tumor with favourable OS and DFS and were living at follow-up. The Spearman correlation coefficient evaluated the $p$-value at 0.001 , furthermore underlined by the Mann-Whitney$U$-Test $p=0.001$. ROC analysis revealed an AUC value of 0.725 (see Fig. 4).

\section{Patient survival}

Analysing the patient collective who remained alive in the follow-up period in regards to patient survival, showed statistically significant differences in eotaxin values in correlation to the CTC status. The box-plot analysis revealed that the living patient collective, being CTC-negative, display higher levels of eotaxin compared to the reduced values of eotaxin in the living patient group, being CTC-positive. 

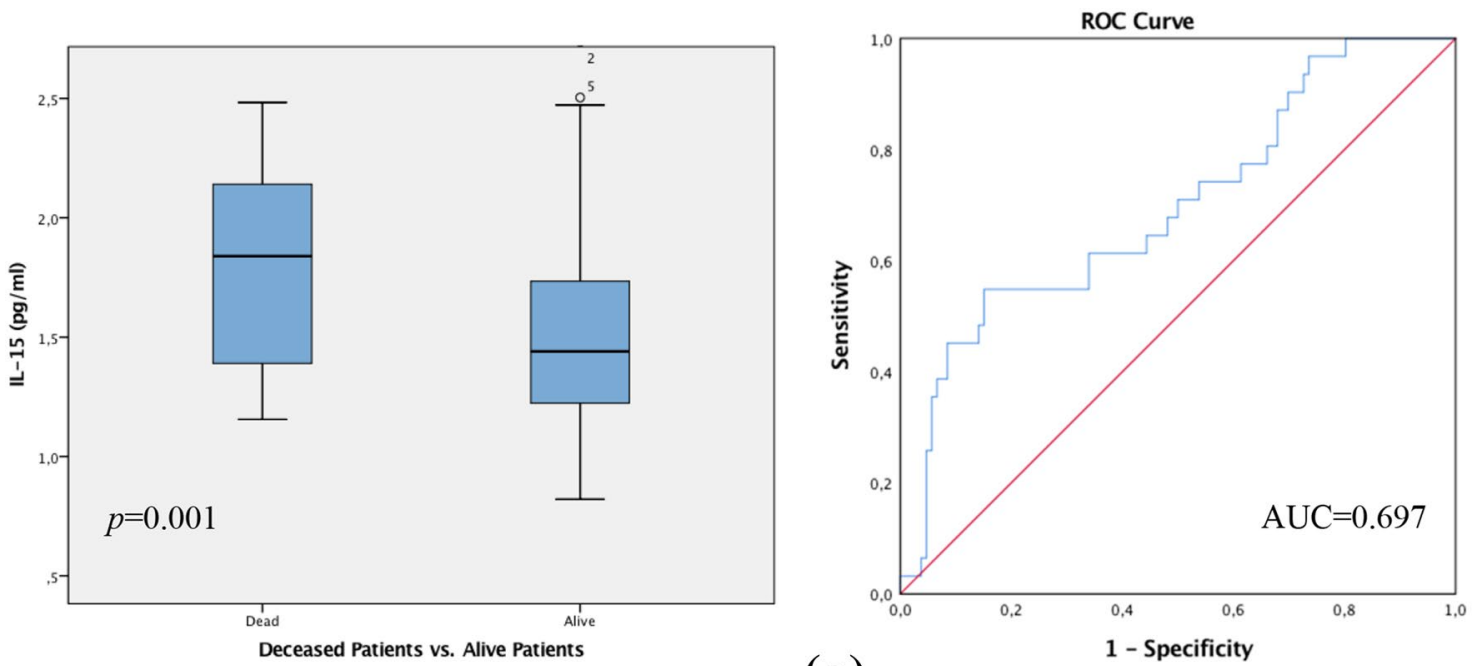

(a)
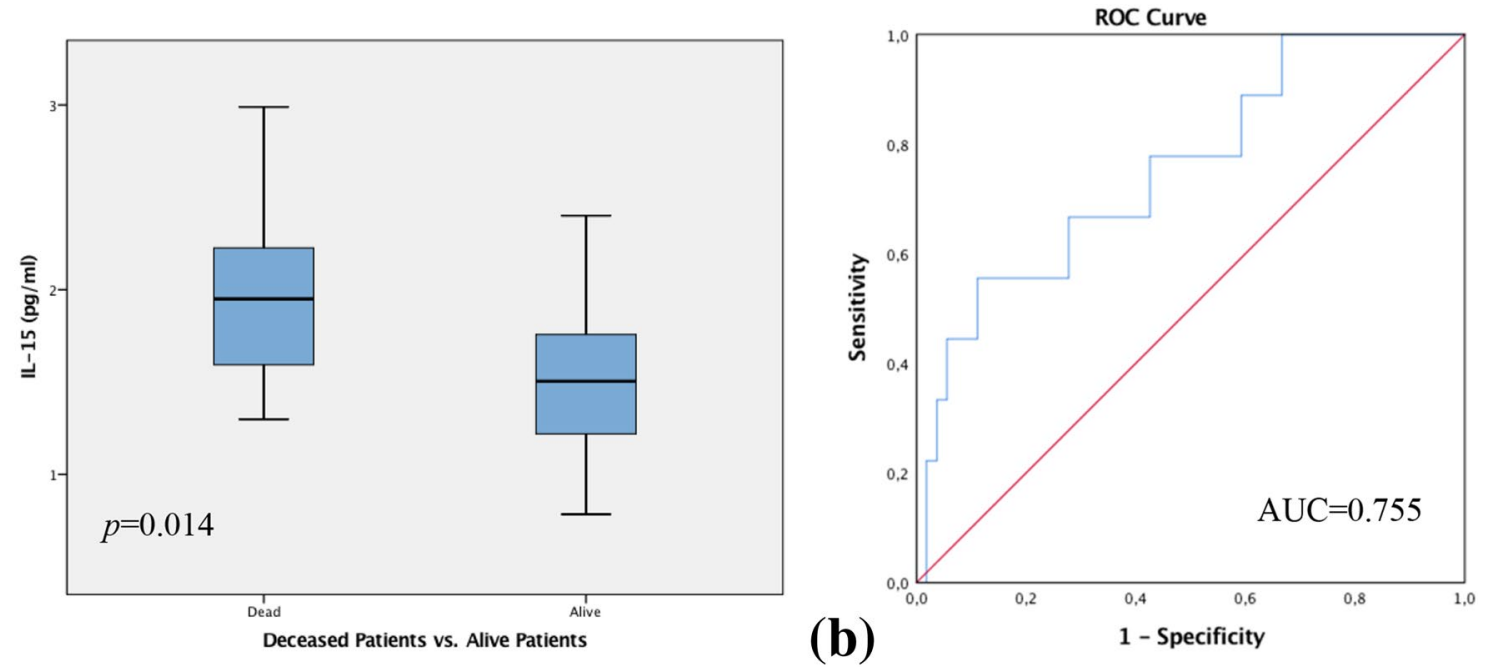

Fig. 2 a Box plot analysis of IL-15 expression in the sera of patients with lymph node metastasis who died in the follow-up period, demonstrate considerably increased IL-15 values in contrast to the notable low IL-15 levels in patients with lymph node metastasis who were living up to follow-up $(p=0.001)$. b Box plot analysis showing the collective of patients with no lymph node involvement (N0) that died during the follow-up period. This group demonstrate significantly higher levels of IL-15 in contrast to the significantly decreased IL-15

The Spearman correlation coefficient assessed the $p$-value at 0.017 which was also supported by the Mann-Whitney$U$-Test $p=0.016$. To continue, ROC analysis was performed, displaying an AUC value of 0.609 (see Fig. 5).

\section{Discussion}

Within this study we analyzed the distribution of IL-15 and eotaxin concentrations and reveal the differences in their expression in the sera of breast cancer patients with and levels in patients who remained alive $(p=0.014)$. The range amongst the 25 th and 75 th percentiles is demonstrated by boxes with a horizontal line at the median. The bars display the 5th and 95th percentiles. Circles specify values more than 1.5 box lengths. Asterisks specify values (marked with a number) more than 3.0 box lengths from the 75th percentile. Receiver operator curve analysis of sensitivity versus specificity gave an area under the curve (AUC) of 0.697 (a) and $0.755(\mathbf{b})$, respectively

without circulating tumor cells. Prior studies have established the role of IL-15 in various tumor identities such as haematological malignancies [38, 46-48], colon cancer [32] or prostate cancer [49]. A clinical trial concerning adult acute lymphoblastic leukaemia even specified that higher IL-15 concentration was significantly associated with a poorer outcome and decreased survival rates compared to decreased serum concentrations of IL-15 in the control group of normal healthy individuals [48]. IL-15 levels are being discussed to be used as a specific tumor biomarker for prognostic values $[28,46]$. Nevertheless, the prognostic role 

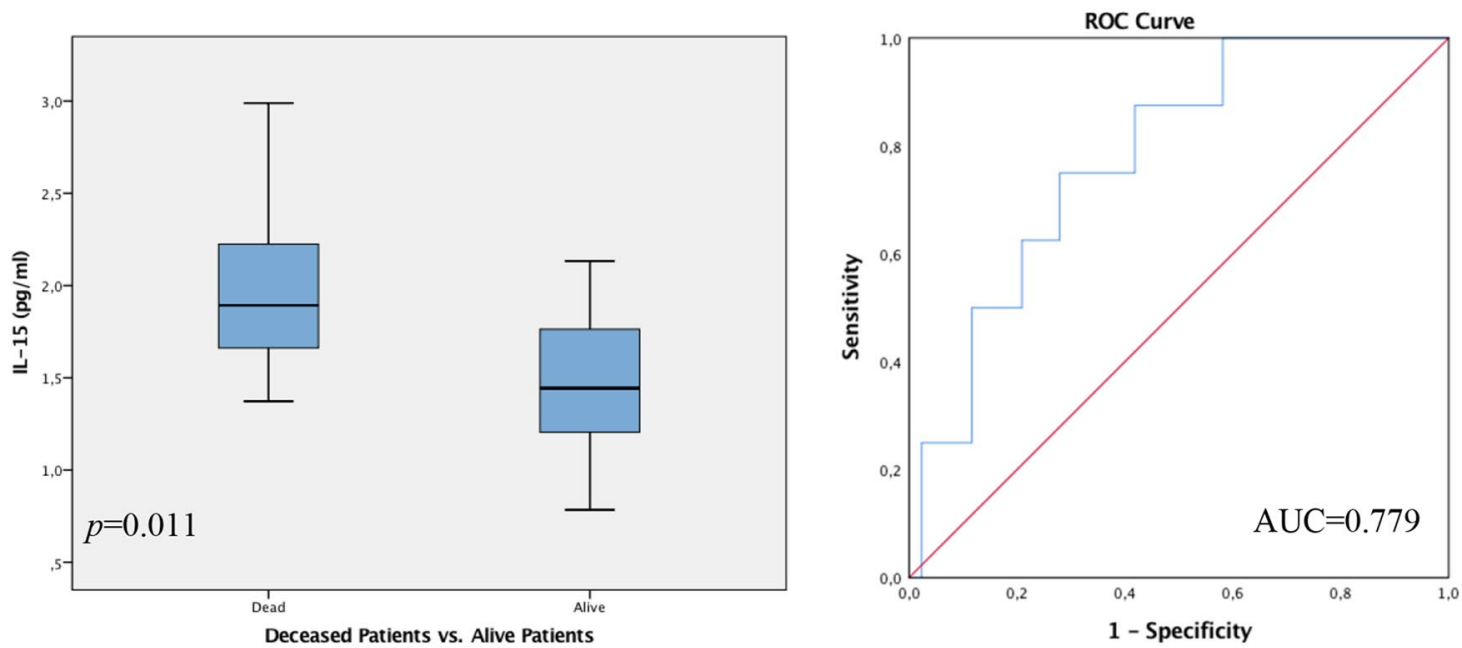

(a)
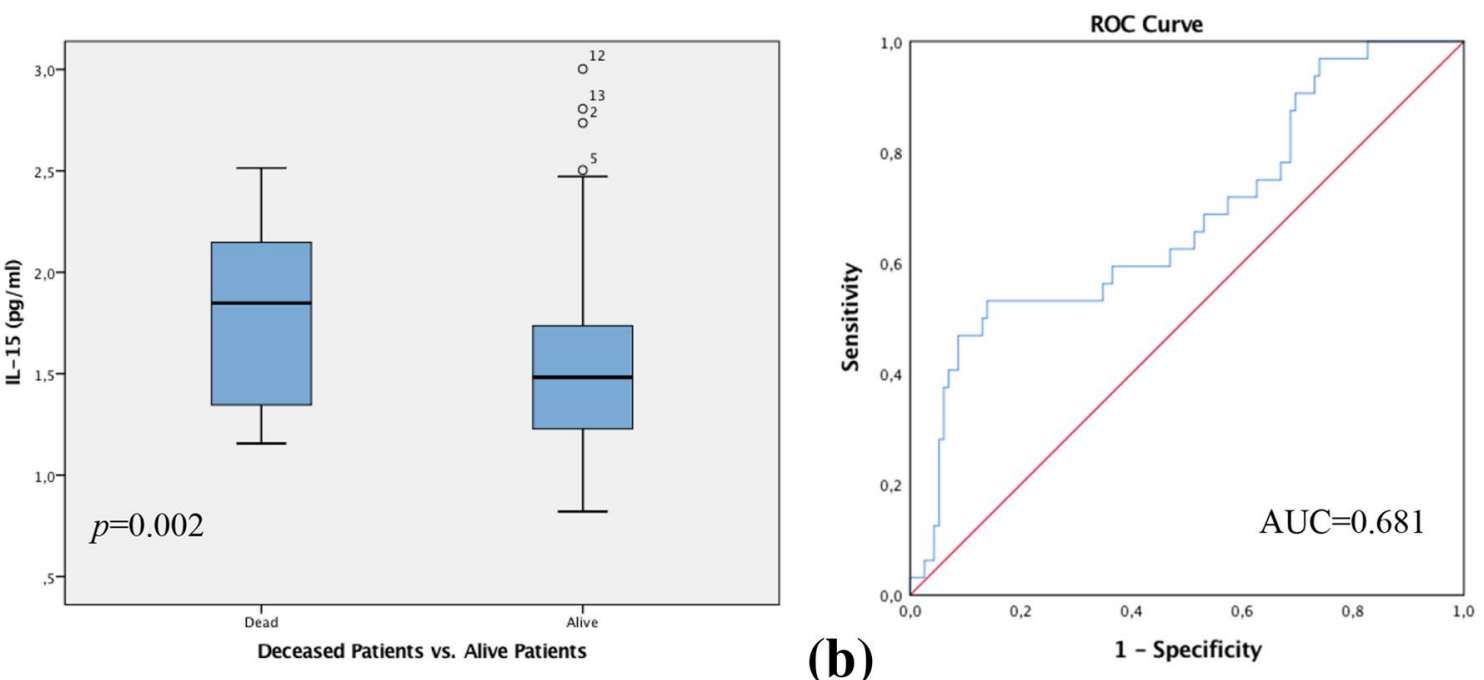

Fig. 3 a Box plot analysis of IL-15 expression in the sera of patients with triple-negative breast cancer. Amongst this patient group, deceased patients expressed drastically higher levels of IL-15 compared to decreased IL-15 values in patients who remained alive $(p=0.011)$. b Similarly, we preformed a box plot analysis of IL-15 expression in the sera of patients with triple-positive breast cancer. Those patients with poor OS and DFS also displayed significantly higher levels of IL-15 in contrast to those patients who remained

of IL-15 in breast cancer remains uncertain. In this study, we found that the serum concentration of IL-15 in breast cancer patients was significantly increased amongst those patients with poor OS and DFS and who had died at followup. In the overall patient collective, and regardless of their CTC-status, lymph node involvement or hormone receptor status, those patients with the poorest OS and DFS expressed significantly higher levels of serum IL-15 compared to those patients with the best survival outcome, which showed low IL-15 concentrations. Nevertheless, elevated serum concentrations of IL-15 significantly correlate to those patients with alive with a triple-positive breast cancer $(p=0.002)$. The range amongst the 25th and 75th percentiles is demonstrated by boxes with a horizontal line at the median. The bars display the 5th and 95th percentiles. Circles specify values more than 1.5 box lengths. Asterisks specify values (marked with a number) more than 3.0 box lengths from the 75th percentile. Receiver operator curve analysis of sensitivity versus specificity gave an area under the curve (AUC) of 0.779 (a) and an AUC of 0.681 (b)

a Grade 3 tumor. Patients with poor OS who died during the follow-up period demonstrated considerably increased IL-15 values in contrast to the significantly low IL-15 levels in patients with a Grade 3 tumor and positive survival outcome. IL-15 values were also significantly decreased in patients with a Grade 2 tumor.

However, studies have indicated that IL-15 can lead to both a favourable and an unfavourable diagnosis, differing by the type of tumor. It is predicted that the inconsistent function of IL-15 in tumors lies within the different immune effects or single nucleotide polymorphism [46]. 

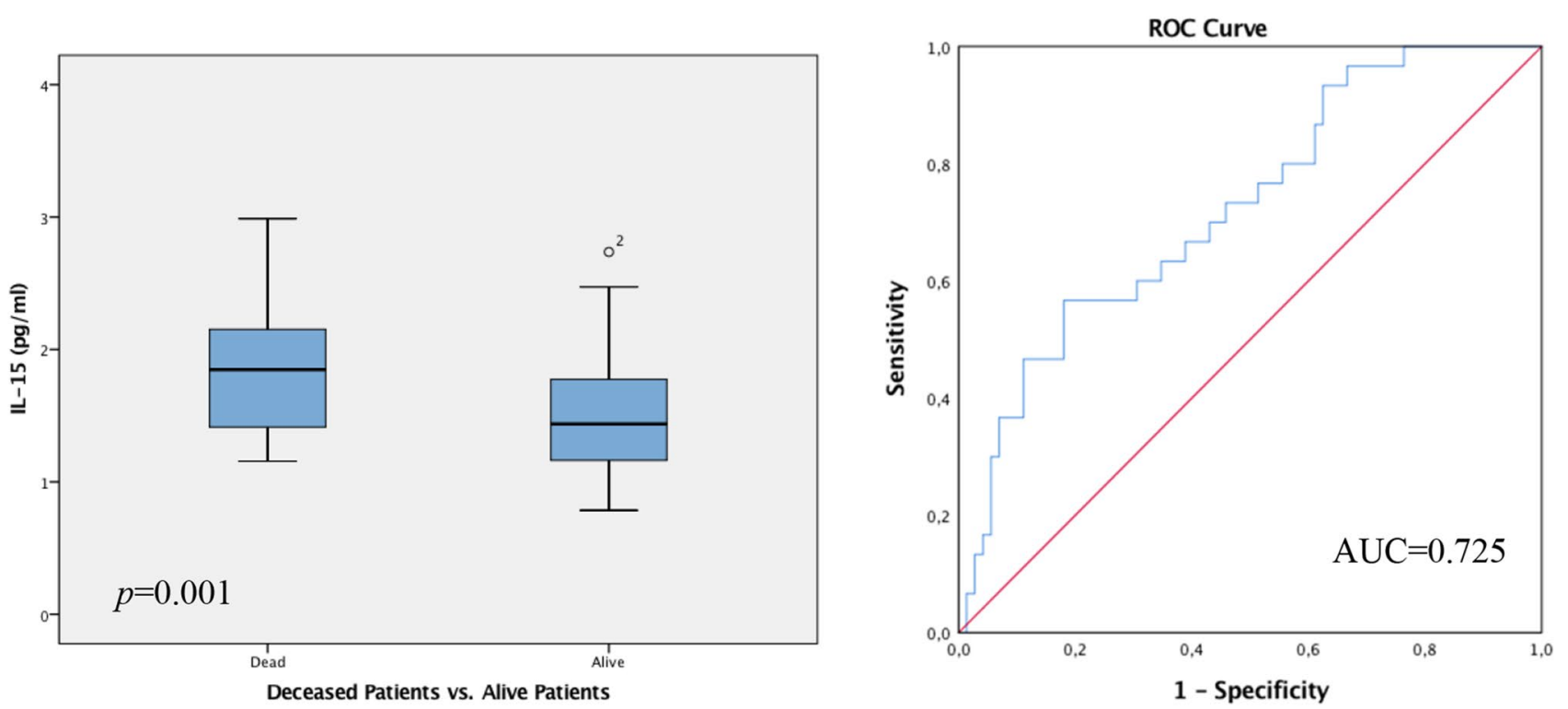

Fig. 4 Box plot analysis of IL-15 expression in the sera of patients with G3 tumor. IL-15 release was significantly higher in the G3 patient collective who died during the follow-up period in contrast to low IL-15 levels in living patients at follow up with a G3 tumor $(p=0.001)$. The range amongst the 25 th and 75 th percentiles is demonstrated by boxes with a horizontal line at the median. The bars dis- play the 5th and 95th percentiles. Circles specify values more than 1.5 box lengths. Asterisks specify values (marked with a number) more than 3.0 box lengths from the 75 th percentile. Receiver operator curve analysis of sensitivity versus specificity gave an area under the curve (AUC) of 0.725
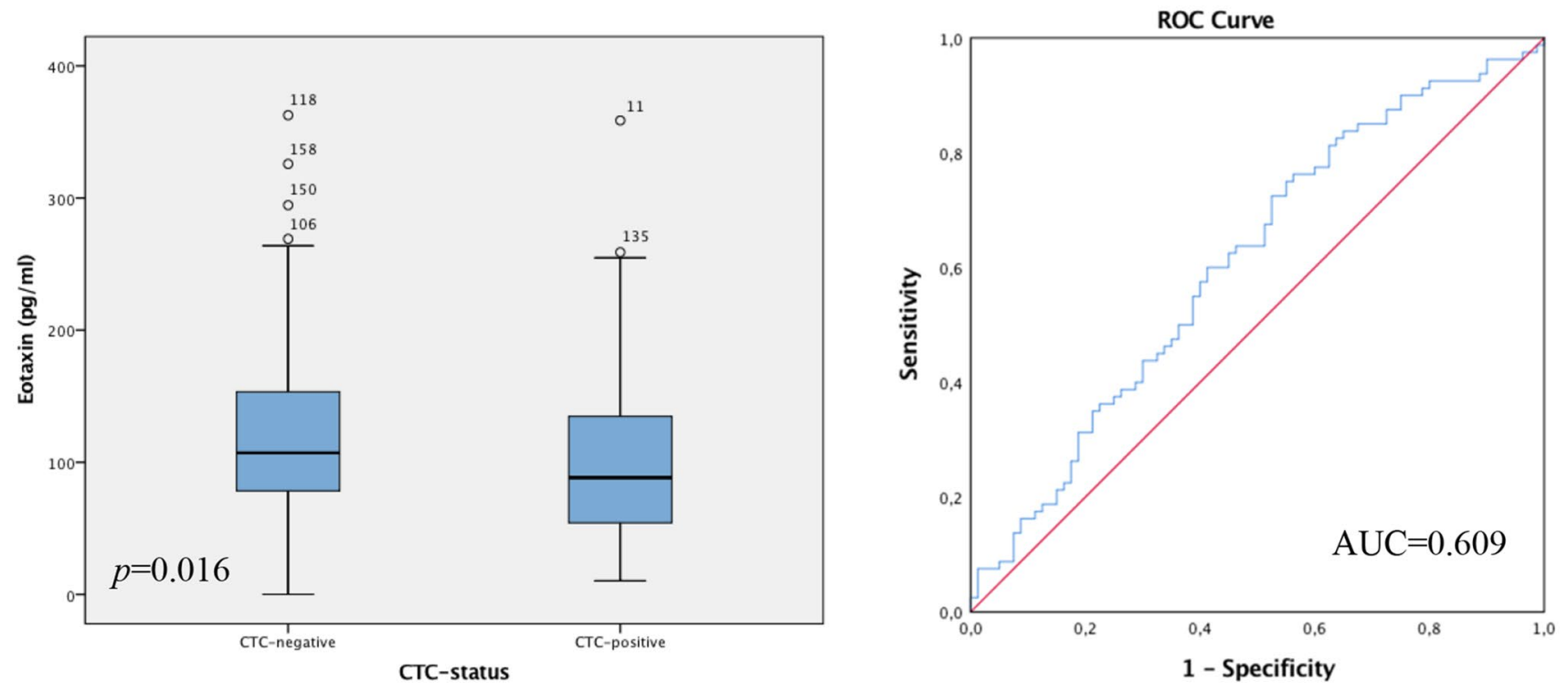

Fig. 5 Box plot analysis of eotaxin expression in the sera of patients who remained alive up to follow-up. The patient group with the most favourable OS and DFS, furthermore CTC-negative, express increased eotaxin values compared to the reduced levels of eotaxin in the living patient group being CTC-positive $(p=0.016)$. The range amongst the 25 th and 75 th percentiles is demonstrated by boxes with a horizontal line at the median. The bars display the 5th and 95th percentiles. Circles specify values more than 1.5 box lengths. Asterisks specify values (marked with a number) more than 3.0 box lengths from the 75th percentile. Receiver operator curve analysis of sensitivity versus specificity gave an area under the curve (AUC) of 0.609 
Rohena-Rivera et al. for example focused on determining the role of IL-15 in prostate cancer using in vitro and in vivo models by administrating IL-15 injections directly into the tumor tissue [49]. Blum et al. suggested that the presence of IL-15 caused inflammation, increased neutrophil infiltration, decreased the number of blood vessels, and was thus positively associated with biochemical recurrent-free survival in prostate cancer patients [50]. Nevertheless, these studies focused on the microenvironment of the tumor itself, suggesting that IL-15 expression, when found in the microenvironment, may provide a benefit for patients $[49,51]$. Similarly, Kunivasu et al. defined IL-15 as a stimulus and attractant to Natural Killer $\mathrm{T}$-cells (NK) and its expression is subsequently considered to be a protective trigger against the progression of certain tumor identities [30, 31, 35, 52]. Nevertheless, it has also been proven that in progressive tumors the infiltration of NK-cells into neoplasms suppressed the activity of the NK-cells [33, 34, 53]. Kunivasu et al. described IL-15 to have an opposite biological effect in colon cancer cells to that in the host immune system. IL-15 expressed on colon epithelial cells and cancer cells can promote the growth of cancer cells [23, 32, 54], while its stimulation on NK cells has an antitumor effect $[35,55]$. Our study has shown that in this scenario both the IL-15-producing breast cancer cell and the patients' host immune system producing IL-15, show a pro-tumor effect and promote tumor progression and metastasis. Our data indicate that when IL-15 can be detected in the sera of patients, its presence might contribute to the process of angiogenesis and progression of the disease thus resulting in a poorer survival outcome.

The association and exact mechanism of increased serum IL-15 levels and unfavourable prognosis are nevertheless not well defined so far. Numerous hypothetical justifications have however been proposed. IL-15 has been described to cause an increased invasion of inflammatory cells to the tumor site and proliferation of adipocytes that consequently cause an increase in size. In addition to the proliferation effect of IL-15, studies on the metastatic potential have shown an up-regulation of desmin and a-sma expression, both markers suggesting a stimulation to metastasis through IL-15 [49]. These results support our findings of increased IL-15 levels in deceased patients. IL-15 in in vitro and in vivo studies has been proven to increase the tumor volume as a consequence of inflammation and lipid mobilization $[49,56]$. Wang et al. described the cell proliferation caused by IL-15, is mechanically induced by a strong proliferative signal by the JAK/STAT and Ras/MAPK pathway, and by increasing the anti-apoptotic proteins Bcl-2 and Bcl-Xl it can inhibit cell death [46, 57]. Furthermore, IL-15 decreases proapoptotic proteins such as BIM, PUMA by the activation of the PI3 K pathway [58-61]. Conversely, to reveal the exact biochemical and cellular function of IL-15 mediated stimulation in breast cancer, additional studies are needed.

IL-15 is a member of the 4 alpha helix group of cytokines, acting via its effective specific receptor IL-15R $\alpha$, that is expressed on antigen-presenting dendritic cells, monocytes and macrophages [62]. IL-15 demonstrates wide-ranging activity and can induce the differentiation and proliferation of T- B- and NK cells. IL-15 is furthermore known to stimulate the differentiation and immunoglobulin synthesis by B cells and has the ability to induce maturation of DCs [24, 62]. Studies have shown that DCs could cause this discrepancy of IL-15 levels acting both as a positive or a negative marker in regard to tumor evolution and survival outcome and its effect on the Immune system [63-65]. DCs, one of the most crucial components of the antigenpresenting stimulation pathway can have a massive impact on the regulation of anti-tumor immune responses [41]. DC based immunotherapies, thoroughly tested in liver cancer, are believed to contribute to the eradication of residual and recurrent tumor cells. It was suggested that mature DCs stimulated with OK432 produce large amounts of $\mathrm{T}$ helper type 1 (Th1) cytokines [66]. IL-15 is known to prime T lymphocytes and NK cells when secreted by DCs and to then stimulate anti-tumor immune responses [67, 68]. Studies have focused on enhancing tumor antigen presentation to T lymphocytes by transferring activated DCs with major histocompatibility, co-stimulatory molecules and loaded with tumor-associated antigens [69-73]. It has been suggested that transferred activated DCs result in higher concentrations of IL-15 and the chemokine eotaxin in the tumor, and collectively proposes that a DC-based, active immunotherapeutic strategy in combination with loco-regional treatment exerts beneficial anti-tumor effects against liver cancer and in DFS [63]. In contrast, it was reported that immature DC infused precisely into tumor tissues also contributed to the recruitment and activation of immune cells such as IL-15 in situ, however, this approach by itself generated limited anti-tumor effects due to probably insufficient stimulation of immature DCs $[63,74]$ and had no effect on prolonged recurrence-free survival. These studies therefore propose that the cytokine profile expressed by dendritic cells is dependent on the cell subtype and mode of activation whereas the concentration and presence of IL-15 itself does not correlate with a beneficial anti-tumor effect but indicates a close relation to the effectiveness of the DCs in regard to preventing tumor cell growth and survival.

On the other hand, eotaxin is known to selectively recruit eosinophils, act as a chemo-attractant, playing a major role in the inhibition of pro-angiogenetic factors, and thus resulting in an anti-tumor effect $[39,40,75]$. Eotaxin has been described to act as an important factor in the down regulation of angiogenesis by decreasing the stimulus for neo-vascularisation [76]. The development of invasive, aggressive 
and metastatic breast cancer is essentially reliant on the neo-vascularisation to provide blood supply for the nourishment and progress of the tumor. Accordingly, the increased eotaxin concentrations in the CTC negative collective could cause a significant interruption of tumor vascularization thus preventing CTCs being released into the peripheral blood by inhibiting circulation specific metastasis. A noteworthy delay in tumor growth could ensue in the absence of CTCs in those patients, subsequently enhancing survival and resulting in a favourable outcome.

The limitation of this study is the relatively short median follow-up period of 65 months. As previously described by Rack et al., the relative short follow-up period in the context of good prognosis results in minor absolute differences in the rate of recurrence and death. Further limitations are the lack of data on $\mathrm{Ki}-67$ in the patient collective. This could be an advantage for more accurate subdivision of different breast cancer subtypes. The disproportional distribution of patient samples, considering 160 living patients, at last observation, and 40 deceased patients at the end of the follow-up period, could lead to limited statistical power. The limited sample size of 200 patients can be regarded as a limitation itself. It would be of interest to test for chemokine and cytokine levels in the overall collective of the SUCCES study group.

To sum up, accumulating evidence suggests IL-15 can initiate and promote certain types of malignancies. Nonetheless, an anti-tumour effect of IL-15 on the immune system has also been hypothesized in experimental trials $[67,68]$ and the activation of IL-15 is currently of major interest in several clinical Phase I trials $[63,74]$. Tinhofer et al. have explored the expression patterns of the particularly sensitive IL-15 signalling pathway for multiple myeloma, a disease defined by the accumulation of malignant plasma cells in the bone marrow. Since IL-15 is also up-regulated in the sera of patients with multiple myeloma, it has been found that those malignant plasma cells expressed all three components of the IL-15R heterotrimer [26-28]. In contrast, normal B-cells from healthy donors downregulate IL-15R $\alpha$ in response to IL-15. IL-15 overexpression in malignant plasma cells in in-vitro studies suggests a protection from spontaneous apoptosis and initiation of induced cell death [26-28, 38]. The data, similarly to our findings, imply that breast cancer and multiple myeloma cells are likely to reduce apoptosis and fortify themselves via autocrine IL-15 stimulation, thus becoming less dependent upon their microenvironment. In order to clarify the exact cellular mechanism of IL-15 resolved signalling in breast cancer, further studies are needed. Early trials in several solid tumors are showing significant clinical responses in patients who are treated with agents that block negative regulators of $\mathrm{T}$ cell activation [69-73]. Nonetheless it is suggested that chronic stimulation can lead to malignant transformation of $\mathrm{T}$ and NK cells and appear to encourage its oncogenic properties. Exploiting IL-15's influential properties to improve lymphocyte effector function in the setting of malignancy is likely to become more structured in the future and might lead to a broader use in the treatment of tumor malignancies.

These findings for the first time demonstrate the functional interaction of increased IL-15 concentrations in the peripheral blood and poor OS and DFS, regardless of the CTC status, lymph node metastasis, or hormone receptor status. A close relationship of increased IL-15 levels in patients with a Grade 3 breast tumor and those with the poorest survival outcome were moreover confirmed. These outcomes imply a substantial function of IL-15 in the pathogenesis of breast cancer and thus could offer new insights into tumor evolution and possible therapeutic approaches. Serum IL-15, simply measured in the everyday clinical routine, could therefore be an independent prognostic marker of major importance in terms of DFS and OS for breast cancer patients. The immense impact of IL-15 as an independent marker for predicting the survival outcome is furthermore underlined by the fact that even in the patient collective with favourable tumor characteristics at primary diagnosis, such as CTC negativity, no lymph node involvement or triple-positive breast cancer, and increased serum IL-15 concentrations were significantly increased in those patients that deceased. Bearing this in mind, IL-15 could be used as an early marker to highlight high-risk patients and the subsequent adjustment of the cancer therapy strategy. In contrast, it can also prevent over treatment in those patients with decreased IL-15 levels. The increased levels of the chemokine eotaxin in CTC negative patients with the best OS and DFS outcome on the other hand, suggests that the overexpression in tumor cells inhibits CTCs entering the peripheral blood, thus emphasizing a significant antiangiogenic effect, inhibiting tumor growth and metastasis. Furthermore, in regard to CTC negativity, the eotaxin value may potentially serve as a predictive marker.

Acknowledgements The authors want to thank Christina Kuhn and Simone Hofmann for technical help with the ELISA system. In addition, we thank Leonie Majunke for the acquisition of the study population data and the provision of the database. We thank Meso Scale Discovery ${ }^{\circledR}$, Rockville, USA for the charge free relinquishment of the MESO QuickPlex SQ 120 system. The study was funded by the Department of Obstetrics and Gynecology of the LMU Munich.

Author contributions T.V. performed the study and made substantial contributions to collecting and interpretation of data and drafting the manuscript. U.J. conceived and designed the study. J.M. was involved in drafting the manuscript, revising it critically for important intellectual content, analysis and interpretation of data. E.T, H.H. and L.S where involved in revising the manuscript. B. R. and W.J. designed the SUCCESS Study and provided materials. T. W. was involved in collection of data, analysis and interpretation of data. 
Funding Open Access funding enabled and organized by Projekt DEAL.

\section{Compliance with ethical standards}

Conflict of interest The authors declare no conflict of interest.

Ethical approval The study was approved by 37 German ethical boards (lead ethical board: LMU, Munich) and conducted in agreement with the Declaration of Helsinki.

Informed consent All patients gave written informed consent and accepted to participate in the SUCCESS study (www.success-studi e.de).

Open Access This article is licensed under a Creative Commons Attribution 4.0 International License, which permits use, sharing, adaptation, distribution and reproduction in any medium or format, as long as you give appropriate credit to the original author(s) and the source, provide a link to the Creative Commons licence, and indicate if changes were made. The images or other third party material in this article are included in the article's Creative Commons licence, unless indicated otherwise in a credit line to the material. If material is not included in the article's Creative Commons licence and your intended use is not permitted by statutory regulation or exceeds the permitted use, you will need to obtain permission directly from the copyright holder. To view a copy of this licence, visit http://creativecommons.org/licenses/by/4.0/.

\section{References}

1. McGuire S (2016) World Cancer Report 2014. Geneva, Switzerland: World Health Organization, International Agency for Research on Cancer, WHO Press, 2015. Adv Nutr 7(2):418-419.

2. Fisher B, Costantino JP, Wickerham DL, Cecchini RS, Cronin WM, Robidoux A, Bevers TB, Kavanah MT, Atkins JN, Margolese RG et al (2005) Tamoxifen for the prevention of breast cancer: current status of the National Surgical Adjuvant Breast and Bowel Project P-1 study. J Natl Cancer Inst 97(22):1652-1662

3. Cauley JA, Norton L, Lippman ME, Eckert S, Krueger KA, Purdie DW, Farrerons J, Karasik A, Mellstrom D, Ng KW et al (2001) Continued breast cancer risk reduction in postmenopausal women treated with raloxifene: 4-year results from the MORE trial. Multiple outcomes of raloxifene evaluation. Breast Cancer Res Treat 65(2):125-134

4. Goss PE, Ingle JN, Ales-Martinez JE, Cheung AM, Chlebowski RT, Wactawski-Wende J, McTiernan A, Robbins J, Johnson KC, Martin LW et al (2011) Exemestane for breast-cancer prevention in postmenopausal women. N Engl J Med 364(25):2381-2391

5. Khazal KF, Hill DL (2015) Withania somnifera extract reduces the invasiveness of MDA-MB-231 breast cancer and inhibits cytokines associated with metastasis. J Cancer Metastasis Treat 1(2):94-100

6. Fisher B, Costantino JP, Wickerham DL, Redmond CK, Kavanah M, Cronin WM, Vogel V, Robidoux A, Dimitrov N, Atkins J et al (1998) Tamoxifen for prevention of breast cancer: report of the National Surgical Adjuvant Breast and Bowel Project P-1 Study. J Natl Cancer Inst 90(18):1371-1388

7. Economopoulou P, Georgoulias V, Kotsakis A (2017) Classifying circulating tumor cells to monitor cancer progression. Expert Rev Mol Diagn 17(2):153-165
8. Banys-Paluchowski M, Krawczyk N, Meier-Stiegen F, Fehm T (2016) Circulating tumor cells in breast cancer-current status and perspectives. Crit Rev Oncol Hematol 97:22-29

9. Li JB, Jiang ZF (2016) Research progress of circulating tumor cells: the way from counting to subtyping. Zhonghua Zhong Liu Za Zhi 38(12):881-885

10. Cristofanilli M, Budd GT, Ellis MJ, Stopeck A, Matera J, Miller MC, Reuben JM, Doyle GV, Allard WJ, Terstappen LW et al (2004) Circulating tumor cells, disease progression, and survival in metastatic breast cancer. N Engl J Med 351(8):781-791

11. Bidard FC, Vincent-Salomon A, Sigal-Zafrani B, Dieras V, Mathiot C, Mignot L, Thiery JP, Sastre-Garau X, Pierga JY (2008) Prognosis of women with stage IV breast cancer depends on detection of circulating tumor cells rather than disseminated tumor cells. Ann Oncol 19(3):496-500

12. Botteri E, Sandri MT, Bagnardi V, Munzone E, Zorzino L, Rotmensz N, Casadio C, Cassatella MC, Esposito A, Curigliano G et al (2010) Modeling the relationship between circulating tumour cells number and prognosis of metastatic breast cancer. Breast Cancer Res Treat 122(1):211-217

13. Daskalaki A, Agelaki S, Perraki M, Apostolaki S, Xenidis N, Stathopoulos E, Kontopodis E, Hatzidaki D, Mavroudis D, Georgoulias V (2009) Detection of cytokeratin-19 mRNA-positive cells in the peripheral blood and bone marrow of patients with operable breast cancer. Br J Cancer 101(4):589-597

14. Hayes DF, Cristofanilli M, Budd GT, Ellis MJ, Stopeck A, Miller MC, Matera J, Allard WJ, Doyle GV, Terstappen LW (2006) Circulating tumor cells at each follow-up time point during therapy of metastatic breast cancer patients predict progression-free and overall survival. Clin Cancer Res 12(14 Pt 1):4218-4224

15. Rack B, Schindlbeck C, Juckstock J, Andergassen U, Hepp P, Zwingers T, Friedl TW, Lorenz R, Tesch H, Fasching PA et al (2014) Circulating tumor cells predict survival in early average-tohigh risk breast cancer patients. J Natl Cancer Inst 2014, 106(5).

16. Bahrami A, Aledavoud SA, Anvari K, Hassanian SM, Maftouh M, Yaghobzade A, Salarzaee O, ShahidSales S, Avan A (2017) the prognostic and therapeutic application of micrornas in breast cancer: tissue and circulating microRNAs. J Cell Physiol 2017.

17. Helal TE, Ibrahim EA, Alloub AI (2013) Immunohistochemical analysis of tumor-infiltrating lymphocytes in breast carcinoma: relation to prognostic variables. Indian J Pathol Microbiol 56(2):89-93

18. Steinman $\mathrm{L}$ (2007) A brief history of $\mathrm{T}(\mathrm{H}) 17$, the first major revision in the $\mathrm{T}(\mathrm{H}) 1 / \mathrm{T}(\mathrm{H}) 2$ hypothesis of $\mathrm{T}$ cell-mediated tissue damage. Nat Med 13(2):139-145

19. Gu-Trantien C, Loi S, Garaud S, Equeter C, Libin M, de Wind A, Ravoet M, Le Buanec H, Sibille C, Manfouo-Foutsop G et al (2013) CD4(+) follicular helper T cell infiltration predicts breast cancer survival. J Clin Investig 123(7):2873-2892

20. Reiner SL (2007) Development in motion: helper T cells at work. Cell 129(1):33-36

21. Weissenbacher T, Hirte E, Kuhn C, Janni W, Mayr D, Karsten U, Rack B, Friese K, Jeschke U, Heublein S et al (2013) Multicentric and multifocal versus unifocal breast cancer: differences in the expression of E-cadherin suggest differences in tumor biology. BMC Cancer 13:361

22. Grabstein KH, Eisenman J, Shanebeck K, Rauch C, Srinivasan S, Fung V, Beers C, Richardson J, Schoenborn MA, Ahdieh $\mathrm{M}$ et al (1994) Cloning of a $\mathrm{T}$ cell growth factor that interacts with the beta chain of the interleukin-2 receptor. Science 264(5161):965-968

23. Carson WE, Giri JG, Lindemann MJ, Linett ML, Ahdieh M, Paxton R, Anderson D, Eisenmann J, Grabstein K, Caligiuri MA (1994) Interleukin (IL) 15 is a novel cytokine that activates human natural killer cells via components of the IL-2 receptor. J Exp Med 180(4):1395-1403 
24. Waldmann TA, Tagaya Y (1999) The multifaceted regulation of interleukin-15 expression and the role of this cytokine in NK cell differentiation and host response to intracellular pathogens. Annu Rev Immunol 17:19-49

25. Jones AM, Griffiths JL, Sanders AJ, Owen S, Ruge F, Harding KG, Jiang WG (2016) The clinical significance and impact of interleukin 15 on keratinocyte cell growth and migration. Int $\mathbf{J}$ Mol Med 38(3):679-686

26. Kukita T, Arima N, Matsushita K, Arimura K, Ohtsubo H, Sakaki Y, Fujiwara H, Ozaki A, Matsumoto T, Tei C (2002) Autocrine and/or paracrine growth of adult T-cell leukaemia tumour cells by interleukin 15. Br J Haematol 119(2):467-474

27. Leroy S, Dubois S, Tenaud I, Chebassier N, Godard A, Jacques Y, Dreno B (2001) Interleukin-15 expression in cutaneous T-cell lymphoma (mycosis fungoides and Sezary syndrome). Br J Dermatol 144(5):1016-1023

28. Tinhofer I, Marschitz I, Henn T, Egle A, Greil R (2000) Expression of functional interleukin-15 receptor and autocrine production of interleukin-15 as mechanisms of tumor propagation in multiple myeloma. Blood 95(2):610-618

29. McInnes IB, Gracie JA (2004) Interleukin-15: a new cytokine target for the treatment of inflammatory diseases. Curr Opin Pharmacol 4(4):392-397

30. Di Carlo E, Meazza R, Basso S, Rosso O, Comes A, Gaggero A, Musiani P, Santi L, Ferrini S (2000) Dissimilar anti-tumour reactions induced by tumour cells engineered with the interleukin-2 or interleukin-15 gene in nude mice. J Pathol 191(2):193-201

31. Gri G, Chiodoni C, Gallo E, Stoppacciaro A, Liew FY, Colombo MP (2002) Antitumor effect of interleukin (IL)-12 in the absence of endogenous IFN-gamma: a role for intrinsic tumor immunogenicity and IL-15. Cancer Res 62(15):4390-4397

32. Kuniyasu H, Ohmori H, Sasaki T, Sasahira T, Yoshida K, Kitadai Y, Fidler IJ (2003) Production of interleukin 15 by human colon cancer cells is associated with induction of mucosal hyperplasia, angiogenesis, and metastasis. Clin Cancer Res 9(13):4802-4810

33. Villegas FR, Coca S, Villarrubia VG, Jimenez R, Chillon MJ, Jareno J, Zuil M, Callol L (2002) Prognostic significance of tumor infiltrating natural killer cells subset CD57 in patients with squamous cell lung cancer. Lung Cancer 35(1):23-28

34. Pross HF, Lotzova E (1993) Role of natural killer cells in cancer. Nat Immun 12(4-5):279-292

35. Tasaki K, Yoshida Y, Miyauchi M, Maeda T, Takenaga K, Kouzu T, Asano T, Ochiai T, Sakiyamna S, Tagawa M (2000) Transduction of murine colon carcinoma cells with interleukin-15 gene induces antitumor effects in immunocompetent and immunocompromised hosts. Cancer Gene Ther 7(2):255-261

36. Giron-Michel J, Giuliani M, Fogli M, Brouty-Boye D, Ferrini S, Baychelier F, Eid P, Lebousse-Kerdiles C, Durali D, Biassoni $\mathrm{R}$ et al (2005) Membrane-bound and soluble IL-15/IL-15Ralpha complexes display differential signaling and functions on human hematopoietic progenitors. Blood 106(7):2302-2310

37. Cario G, Izraeli S, Teichert A, Rhein P, Skokowa J, Moricke A, Zimmermann M, Schrauder A, Karawajew L, Ludwig WD et al (2007) High interleukin-15 expression characterizes childhood acute lymphoblastic leukemia with involvement of the CNS. J Clin Oncol 25(30):4813-4820

38. Chow C, Liu AY, Chan WS, Lei KI, Chan WY, Lo AW (2005) AKT plays a role in the survival of the tumor cells of extranodal NK/T-cell lymphoma, nasal type. Haematologica 90(2):274-275

39. Kataoka S, Konishi Y, Nishio Y, Fujikawa-Adachi K, Tominaga A (2004) Antitumor activity of eosinophils activated by IL-5 and eotaxin against hepatocellular carcinoma. DNA Cell Biol 23(9):549-560

40. Simson L, Ellyard JI, Dent LA, Matthaei KI, Rothenberg ME, Foster PS, Smyth MJ, Parish CR (2007) Regulation of carcinogenesis by IL-5 and CCL11: a potential role for eosinophils in tumor immune surveillance. J Immunol 178(7):4222-4229

41. Banchereau J, Briere F, Caux C, Davoust J, Lebecque S, Liu YJ, Pulendran B, Palucka K (2000) Immunobiology of dendritic cells. Annu Rev Immunol 18:767-811

42. Fritz A, Percy C, Jack A, Shanmugaratnam K, Sobin L, Parkin DM, Whelan S (2000) International Classification of Diseases for Oncology 3. WHO, Genf

43. Elston EW, Ellis IO (1993) Method for grading breast cancer. J Clin Pathol 46(2):189-190

44. Breitbart W, Rosenfeld B, Tobias K, Pessin H, Ku GY, Yuan J, Wolchok J (2014) Depression, cytokines, and pancreatic cancer. Psycho-oncology 23(3):339-345

45. Mitsunaga S, Ikeda M, Shimizu S, Ohno I, Furuse J, Inagaki M, Higashi S, Kato H, Terao K, Ochiai A (2013) Serum levels of IL-6 and IL-1beta can predict the efficacy of gemcitabine in patients with advanced pancreatic cancer. Br J Cancer 108(10):2063-2069

46. Wang H, Zhu JY, Liu CC, Zhu MY, Wang JH, Geng QR, Lu Y (2015) Increased serum levels of interleukin-15 correlate with negative prognostic factors in extranodal NK/T cell lymphoma. Med Oncol 32(1):370

47. Burton JD, Bamford RN, Peters C, Grant AJ, Kurys G, Goldman CK, Brennan J, Roessler E, Waldmann TA (1994) A lymphokine, provisionally designated interleukin $\mathrm{T}$ and produced by a human adult T-cell leukemia line, stimulates T-cell proliferation and the induction of lymphokine-activated killer cells. Proc Natl Acad Sci USA 91(11):4935-4939

48. Barata JT, Keenan TD, Silva A, Nadler LM, Boussiotis VA, Cardoso AA (2004) Common gamma chain-signaling cytokines promote proliferation of T-cell acute lymphoblastic leukemia. Haematologica 89(12):1459-1467

49. Rohena-Rivera K, Sanchez-Vazquez MM, Aponte-Colon DA, Forestier-Roman IS, Quintero-Aguilo ME, Martinez-Ferrer M (2017) IL-15 regulates migration, invasion, angiogenesis and genes associated with lipid metabolism and inflammation in prostate cancer. PLoS ONE 12(4):e0172786

50. Blum DL, Koyama T, M'Koma AE, Iturregui JM, MartinezFerrer M, Uwamariya C, Smith JA Jr, Clark PE, Bhowmick NA (2008) Chemokine markers predict biochemical recurrence of prostate cancer following prostatectomy. Clin Cancer Res 14(23):7790-7797

51. Morris JC, Ramlogan-Steel CA, Yu P, Black BA, Mannan P, Allison JP, Waldmann TA, Steel JC (2014) Vaccination with tumor cells expressing IL-15 and IL-15Ralpha inhibits murine breast and prostate cancer. Gene Ther 21(4):393-401

52. Fehniger TA, Cooper MA, Caligiuri MA (2002) Interleukin-2 and interleukin-15: immunotherapy for cancer. Cytokine Growth Factor Rev 13(2):169-183

53. Schantz SP, Ordonez NG (1991) Quantitation of natural killer cell function and risk of metastatic poorly differentiated head and neck cancer. Nat Immun Cell Growth Regul 10(5):278-288

54. Cao S, Troutt AB, Rustum YM (1998) Interleukin 15 protects against toxicity and potentiates antitumor activity of 5-fluorouracil alone and in combination with leucovorin in rats bearing colorectal cancer. Cancer Res 58(8):1695-1699

55. Bulfone-Paus S, Bulanova E, Pohl T, Budagian V, Durkop H, Ruckert R, Kunzendorf U, Paus R, Krause H (1999) Death deflected: IL-15 inhibits TNF-alpha-mediated apoptosis in fibroblasts by TRAF2 recruitment to the IL-15Ralpha chain. FASEB J 13(12):1575-1585

56. Bub JD, Miyazaki T, Iwamoto Y (2006) Adiponectin as a growth inhibitor in prostate cancer cells. Biochem Biophys Res Commun 340(4):1158-1166

57. Williams MT, Yousafzai Y, Cox C, Blair A, Carmody R, Sai S, Chapman KE, McAndrew R, Thomas A, Spence A et al (2014) Interleukin-15 enhances cellular proliferation and upregulates 
CNS homing molecules in pre-B acute lymphoblastic leukemia. Blood 123(20):3116-3127

58. Huntington ND, Puthalakath H, Gunn P, Naik E, Michalak EM, Smyth MJ, Tabarias H, Degli-Esposti MA, Dewson G, Willis SN et al (2007) Interleukin 15-mediated survival of natural killer cells is determined by interactions among Bim, Noxa and Mcl-1. Nat Immunol 8(8):856-863

59. Steelman LS, Pohnert SC, Shelton JG, Franklin RA, Bertrand FE, McCubrey JA (2004) JAK/STAT, Raf/MEK/ERK, PI3K/Akt and $\mathrm{BCR}-\mathrm{ABL}$ in cell cycle progression and leukemogenesis. Leukemia 18(2):189-218

60. Miyazaki T, Kawahara A, Fujii H, Nakagawa Y, Minami Y, Liu ZJ, Oishi I, Silvennoinen O, Witthuhn BA, Ihle JN et al (1994) Functional activation of Jak 1 and Jak 3 by selective association with IL-2 receptor subunits. Science 266(5187):1045-1047

61. Adunyah SE, Wheeler BJ, Cooper RS (1997) Evidence for the involvement of LCK and MAP kinase (ERK-1) in the signal transduction mechanism of interleukin-15. Biochem Biophys Res Commun 232(3):754-758

62. Steel JC, Waldmann TA, Morris JC (2012) Interleukin-15 biology and its therapeutic implications in cancer. Trends Pharmacol Sci 33(1):35-41

63. Nakamoto Y, Mizukoshi E, Kitahara M, Arihara F, Sakai Y, Kakinoki K, Fujita Y, Marukawa Y, Arai K, Yamashita T et al (2011) Prolonged recurrence-free survival following OK432-stimulated dendritic cell transfer into hepatocellular carcinoma during transarterial embolization. Clin Exp Immunol 163(2):165-177

64. Mizukoshi E, Nakamoto Y, Tsuji H, Yamashita T, Kaneko S (2006) Identification of alpha-fetoprotein-derived peptides recognized by cytotoxic T lymphocytes in HLA-A24+ patients with hepatocellular carcinoma. Int J Cancer 118(5):1194-1204

65. Mizukoshi E, Nakamoto Y, Marukawa Y, Arai K, Yamashita T, Tsuji H, Kuzushima K, Takiguchi M, Kaneko S (2006) Cytotoxic T cell responses to human telomerase reverse transcriptase in patients with hepatocellular carcinoma. Hepatology 43(6):1284-1294

66. Nakahara S, Tsunoda T, Baba T, Asabe S, Tahara H (2003) Dendritic cells stimulated with a bacterial product, OK-432, efficiently induce cytotoxic $\mathrm{T}$ lymphocytes specific to tumor rejection peptide. Cancer Res 63(14):4112-4118
67. de Saint-Vis B, Fugier-Vivier I, Massacrier C, Gaillard C, Vanbervliet B, Ait-Yahia S, Banchereau J, Liu YJ, Lebecque S, Caux C (1998) The cytokine profile expressed by human dendritic cells is dependent on cell subtype and mode of activation. J Immunol 160(4):1666-1676

68. Shanmugham LN, Petrarca C, Frydas S, Donelan J, Castellani ML, Boucher W, Madhappan B, Tete S, Falasca K, Conti P et al (2006) IL-15 an immunoregulatory and anti-cancer cytokine. Recent advances. J Exp Clin Cancer Res 25(4):529-536

69. Lemos MP, Esquivel F, Scott P, Laufer TM (2004) MHC class II expression restricted to CD8alpha+ and CD11b+ dendritic cells is sufficient for control of Leishmania major. J Exp Med 199(5):725-730

70. Ni K, O’Neill HC (1997) The role of dendritic cells in T cell activation. Immunol Cell Biol 75(3):223-230

71. Andrews DM, Andoniou CE, Scalzo AA, van Dommelen SL, Wallace ME, Smyth MJ, Degli-Esposti MA (2005) Cross-talk between dendritic cells and natural killer cells in viral infection. Mol Immunol 42(4):547-555

72. Heiser A, Coleman D, Dannull J, Yancey D, Maurice MA, Lallas CD, Dahm P, Niedzwiecki D, Gilboa E, Vieweg J (2002) Autologous dendritic cells transfected with prostate-specific antigen RNA stimulate CTL responses against metastatic prostate tumors. J Clin Investig 109(3):409-417

73. Banchereau J, Steinman RM (1998) Dendritic cells and the control of immunity. Nature 392(6673):245-252

74. Steinman RM, Banchereau J (2007) Taking dendritic cells into medicine. Nature 449(7161):419-426

75. Farmaki E, Kaza V, Papavassiliou AG, Chatzistamou I, Kiaris H (2017) Induction of the MCP chemokine cluster cascade in the periphery by cancer cell-derived Ccl3. Cancer Lett 389:49-58

76. Georgiou GK, Igglezou M, Sainis I, Vareli K, Batsis H, Briasoulis E, Fatouros M (2013) Impact of breast cancer surgery on angiogenesis circulating biomarkers: a prospective longitudinal study. World J Surg Oncol 11:213

Publisher's Note Springer Nature remains neutral with regard to jurisdictional claims in published maps and institutional affiliations. 